\title{
Association of Morphology and Immunophenotype in Diffuse Large B-Cell Lymphomas with Bone Marrow Infiltration in a Sample Mexican Population*
}

\author{
Mónica-Belinda Romero-Guadarrama ${ }^{1 \#}$, Fiacro Jiménez Ponce ${ }^{1}$, Armando Medina Cruz ${ }^{1}$, \\ Elsa Lorena Durán Ramírez ${ }^{1}$, Icela Palma Lara ${ }^{2}$
}

\begin{abstract}
${ }^{1}$ Unidad de Patología del Hospital General de México, Facultad de Medicina, Universidad Nacional Autónoma de México (UNAM), México City, México; ${ }^{2}$ Molecular and Celular Morphology Laboratory, Escuela Superior de Medicina, Instituto Politécnico Nacional and Morphology Department, Facultad de Medicina Veterinaria y Zootecnia (UNAM), México City, México.

Email: ${ }^{*}$ monicaromero@att.net.mx
\end{abstract}

Received January $26^{\text {th }}, 2012$; revised February $10^{\text {th }}, 2012$; accepted March $12^{\text {th }}, 2012$

\begin{abstract}
Introduction: Diffuse large B-cell lymphoma (DLBCL), not otherwise specified, is a large B-cell lymphoma with a diffuse growth pattern and aggressive clinical course. It is divided in subgroups according to its morphology, immunophenotype, and primary site. Dissemination to bone marrow occurs in $11 \%$ to $35 \%$ of cases and can be of concordant or discordant morphology. Objective: To examine the association, the type of bone marrow involvement in relation to the primary site, morphology, immunohistochemistry of DLBCLs and to determine the cases of Epstein-Barr virus positive DLBCLs. Materials and Methods: We reviewed lymph node and extranodal biopsies as well as the respective bone marrow biopsies in all cases of DLBCL diagnosed in the Hospital General de México during the period from 2002 to 2010. We used immunohystochemistry for immunophenotype identification (Hans's algorithm) and an in-situ hybridization technique to detect presence of Epstein Barr encoded RNA (EBER). Results: We included 108 patients with a mean age of 51.9 years, $59(55 \%)$ were men. DLBCL involved lymph nodes in $60 \%$ of cases and palatine tonsils in $13 \%$. The centroblastic variant predominated $(80 \%)$ and $58 \%$ originated from activated B-cells. Infiltration of bone marrow was present in 30\% of cases and was discordant in 55\% of these cases. Correlation between morphology and bone marrow infiltration was statistically significant $(P=0.0003)$. Presence of Epstein-Barr virus was demonstrated in $15 \%$ of patients older than 50 years. Conclusions: Dissemination to bone marrow occurred in $30 \%$ of cases and discordant involvement was most common. DLBCL originating from activated B-lymphocytes predominated and the most common extranodal sites were palatine tonsils, suggesting that our population has a clinical behavior similar to Asiatic populations.
\end{abstract}

Keywords: Dissemination to Bone Marrow; Diffuse Large B-Cell Lymphoma; Immunophenotype

\section{Introduction}

Diffuse large B-cell lymphoma (DLBCL), not otherwise specified, is a type of non-Hodgkin lymphoma, and comprises a group of clinically aggressive heterogeneous entities. It accounts for $25 \%$ to $30 \%$ of lymphomas in adults in the USA and western Europe [1]. It arises in lymph nodes in $60 \%$ of cases and extranodal sites in $40 \%$. The most common extranodal site is the gastrointestinal tract $(35 \%-37 \%)[1,2]$. Biological, clinical, and morphological studies have classify the DLBCL into morphological, immunophenotypical, and molecular sub-

\footnotetext{
*Disclosure/conflict of interest: The authors declare no conflict of interest.

${ }^{\#}$ Corresponding author.
}

types [3-7]. Dissemination to bone marrow (BM) occurs in advanced clinical stages and varies in different series from $11 \%$ to $35 \%$ [1,2]. Minimal infiltration can be detected if auxiliary studies are conducted together with the morphological evaluation, using immunohistochemistry markers or polymerase chain reaction (PCR) in the bone marrow (BM) specimen biopsy [8]. The prevalence of discordant infiltration varies in different reports and ranges from rare to $70 \%[9,10]$. Dissemination to bone marrow at the time of diagnosis plays a crucial role in determining treatment and predicting clinical follow-up of patients [11]. There are controversial data concerning the prognostic significance of BM involvement in DLBCL, when relying only on routine histology, percentage of medullar involvement, and type of infiltration $[12,13]$. 
Hence, some authors recommend determining BM involvement by other auxiliary methods such as flow cytometry and immunohistochemistry [14].

In a previous study at our institution, we documented that DLBCL accounted for $59 \%$ of all lymphoid neoplasms, and the mean age at diagnosis was 50 years with a predominance for the male sex [3]. In some populations, such as Western Europe and in the United States the mean age at diagnosis is between 60 and 70 years of age but it is also encountered in children and young adults [1-3]. The objective of the present study was to association of morphology, immunophenotype, clinical site of the DLCBL and the presence of Epstein Barr virus with the type of BM infiltration to determine possible prognostic factors at the time of clinical staging.

\section{Materials and Methods}

\section{Case Selection}

We reviewed the biopsy of the primary site of DLCBL and the immunohistochemistry reports filed during the period from 2002 to 2010 at the surgical pathology archives of the Pathology Unit of the General Hospital of Mexico, and selected all cases diagnosed as DLCBL arising in lymph nodes and extranodal sites, such as palatine tonsils, oropharynx, gastrointestinal tract, cervix, and mammary glands, and that had a bone marrow biopsy. We reviewed the histologic sections stained with hematoxylin-eosin, periodic acid-Schiff (PAS), Giemsa, and reticulin. We included BM biopsies that sampled at least 8 - 10 medullary spaces or at least $1 \mathrm{~cm}$ long and determined discordant versus concordant infiltration. We employed the streptavidin-biotin peroxidase technique for immunohistochemistry studies of tissue embedded in paraffin from the primary tumor and BMs with suspected discordant morphology. Antigenic recovery was performed in a pressure boiler, with citrate buffer at a $\mathrm{pH}$ of 8 and pressure of 1 bar (20 PSI) for 30 seconds and subsequently incubated for $40 \mathrm{~min}$ at room temperature. To perform the immunohistochemistry tests, the tissue was cut into $4-\mu \mathrm{m}$ thick sections and deparaffinized. Endogenous peroxidase activity was blocked using methanol and hydrogen peroxide. Subsequently it was washed, placed in phosphate buffered saline, and then incubated with normal sheep serum. The sample was decanted and the primary antibody was incubated for $18 \mathrm{~h}$ at $4^{\circ} \mathrm{C}$, washed, and placed in phosphate buffered saline. The secondary biotin-marked antibody was added for $60 \mathrm{~min}$ and washed with PBS. Streptavidin-biotin was added and the antigen-antibody binding visualized with diaminobenzidine. It was washed under running tap water and then counterstained with Hill hematoxylin, washed, rehydrated, cleared in xylol, and mounted on the corre- sponding slides. The monoclonal antibodies used were CD 20 (L-26 clone Dako Cytomation), CD 5 (clone, CD5/54/B4), CD 2 (rabbit monoclonal antibodies; Dako Cytomation), CD 10 (clone, 56C; Novocastra Laboratories), MUM-1 protein (clone, MUM 1p; Dako Cytomation), bcl2 (clone 124; Dako Cytomation) and bcl6 (clone G-B6p; Dako Cytomation).

The in-situ hybridization technique was carried out using fluorescein-labeled oligonucleotide probes to detect nuclear presence of encoded Epstein Barr RNA (EBER). We added conjugated alkaline phosphatase, rabbit antibody and antifluorescein isothiocyanate, followed by $4-$ nitroblue tetrazolium/5-bromo-4-chloro-3-indolyl phosphate (NBT/BCIP; Roche Diagnostics, Indianapolis, IN, USA). Hill's hematoxylin was used to counter-stain and the procedure was continued as described in the immunohistochemistry technique above. As a positive control we used a nasal T/NK cell lymphoma sample.

The following independent variables were analyzed: age, gender, primary site, and morphological subtype (centroblastic: monomorphic or polymorphic, immunoblastic and anaplastic). The immunohistochemistry markers were reported as positive when at least $30 \%$ of the neoplastic cells showed positivity for CD 10, bcl6, bcl2, and MUM-1. For the in-situ hybridization test, EBER was reported as either negative or positive. The dependent variable, bone marrow infiltration, was judged by the size of lymphoid cells as either discordant (small lymphocyte) or concordant (large lymphocyte with blastic resemblance). Statistical analysis was performed using the SPSS software (version 11) and the level of statistical significance for comparisons was set at $P \leq 0.05$ using $\mathrm{x}^{2}$.

\section{Results}

We evaluated 108 patients who had a suitable bone marrow biopsy. Fifty-nine (55\%) were male and 49 (45\%) were female. The primary sites were localized as follows: lymph nodes $(60.1 \%)$, palatine tonsils $(13 \%)$, ocular adnexa $(6.5 \%)$, digestive tract $(3.7 \%)$, the rest of the primary DLBCL sites included soft tissues, mammary glands and cervix. Skin, mediastinum, and central nervous system was not included (Table 1). The mean age of diagnosis in the patients presenting DLBCL affecting lymph nodes and tonsils was 52 years. For DLCBL affecting ocular adnexa and other extranodal sites, the mean age at diagnosis was 47.8 and 47.9 years, respecttively, while for those primarily affecting the digestive tube, the mean age at diagnosis was 65 years. Concerning morphology, the centroblastic (CB) variant was predominant with 87 cases $(80.5 \%)$. The $\mathrm{CB}$ variant was further subdivided, according to Kiel's classification criteria into polymorphic and monomorphic subtypes, considering the 
Table 1. Association between gender, the morphologic type of DLBCL and the primary site.

\begin{tabular}{|c|c|c|c|c|c|c|c|c|c|c|c|}
\hline \multirow{3}{*}{ DLBCLtype } & \multirow{3}{*}{ Gender } & \multicolumn{10}{|c|}{ Primary site of DLBCL } \\
\hline & & \multicolumn{2}{|c|}{ Lymph nodes } & \multicolumn{2}{|c|}{ Palatine tonsils } & \multicolumn{2}{|c|}{ Ocular adnexa } & \multicolumn{2}{|c|}{ Digestive tract } & \multicolumn{2}{|c|}{ Other extranodal sites } \\
\hline & & Count & Column N \% & Count & Column N \% & Count & Column N \% & Count & Column N \% & Count & Column N \% \\
\hline \multirow{2}{*}{ Polymorphic } & Female & 15 & 40.5 & 5 & 41.7 & 3 & 50.0 & 1 & 100.0 & 5 & 71.4 \\
\hline & Male & 22 & 59.5 & 7 & 58.3 & 3 & 50.0 & 0 & 0.0 & 2 & 28.6 \\
\hline \multirow{2}{*}{ Monomorphic } & Female & 6 & 42.9 & 1 & 100.0 & 1 & 100.0 & 0 & 0.0 & 3 & 60.0 \\
\hline & Male & 8 & 57.1 & 0 & 0.0 & 0 & 0.0 & 2 & 100.0 & 2 & 40.0 \\
\hline \multirow{2}{*}{ Immunoblastic } & Female & 3 & 42.9 & 0 & 0.0 & 0 & 0.0 & 0 & 0.0 & 1 & 50.0 \\
\hline & Male & 4 & 57.1 & 0 & 0.0 & 0 & 0.0 & 0 & 0.0 & 1 & 50.0 \\
\hline \multirow{2}{*}{ Anaplastic } & Female & 2 & 40.0 & 0 & 0.0 & 0 & 0.0 & 0 & 0.0 & 3 & 100.0 \\
\hline & Male & 3 & 60.0 & 1 & 100.0 & 0 & 0.0 & 1 & 100.0 & 0 & 0.0 \\
\hline
\end{tabular}

number of immunoblasts, centrocytes, and centrocytoid cells. Sixty-four $(73.5 \%)$ cases were classified as polymorphic CB (Figure 1(a)) and $23(26.4 \%)$ cases as monomorphic CB (Figure 1(b)). Eleven (10.1\%) were classified as anaplastic and $10(9.2 \%)$ as immunoblastic lymphomas (IB) (Table 1). Considering immunohistochemical marker expression, lymphomas that were positive for CD 10 and Bcl6 (28.7\%) were considered as deriving from germinal center (GC) B-cells (Figure 2(a)), whereas those expressing Mum-1 (Figure 2(b)) and lacking CD 10 expression (58.3\%) were considered as deriving from activated $\mathrm{B}$-cells $(\mathrm{ABC})$ or non-GC cells. Lymphomas expressing only bcl 2 markers were considered as a third type and corresponded to $12.9 \%$ of cases. (Table 2).

Infiltration to bone marrow was documented in $30.6 \%$ of cases, and the mean age at detection of BM infiltration was 54.8 years. Infiltration was determined as discordant in 55\% (Figures 3(a) and (b)) and concordant (Figures $4(\mathbf{a})$ and (b)) in $45 \%$ of cases. BM infiltration by site was most common in lymph node with 21 of 65 cases, followed by tonsils with 3 of 11 cases showing BM infiltration and digestive tube with 3 of 7 cases showing BM infiltration. DLBCL of primary sites corresponding to eyes, adnexa, and other sites (22 cases) showed BM infiltration in 6 cases $(5.5 \%)(P=0.638)$.

Regarding morphology and BM infiltration, we documented that the $\mathrm{CB}$ variant was most frequently associated to BM involvement (29 cases). The percentage of BM infiltration in the polymorphic $(45.5 \%)$ and monomorphic subtypes $(42.4 \%)$ was similar $(P=0.0003)$ (Table 3). Three cases of immunoblastic lymphomas ( $9 \%)$ and one case of anaplastic lymphoma (3\%) showed BM infiltration (Table 4). Correlation between immunophenotype and BM infiltration showed that 10 out of 31

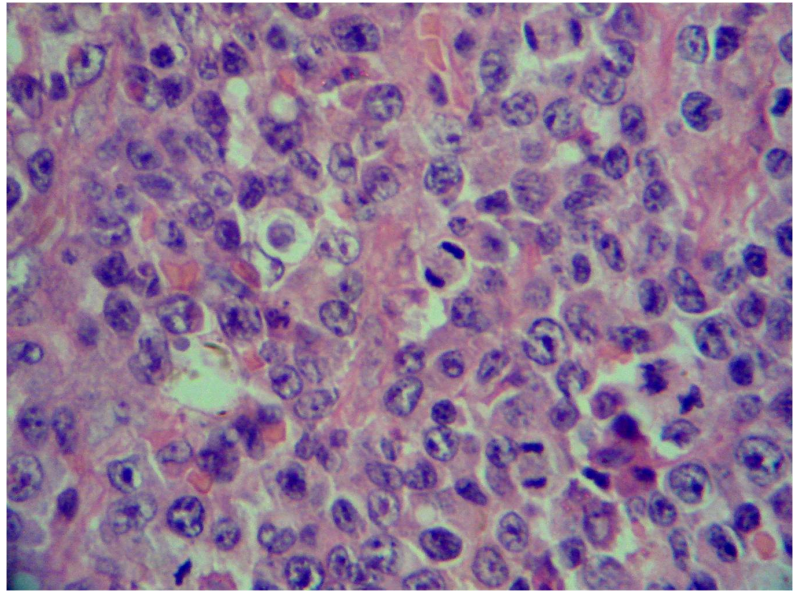

(a)

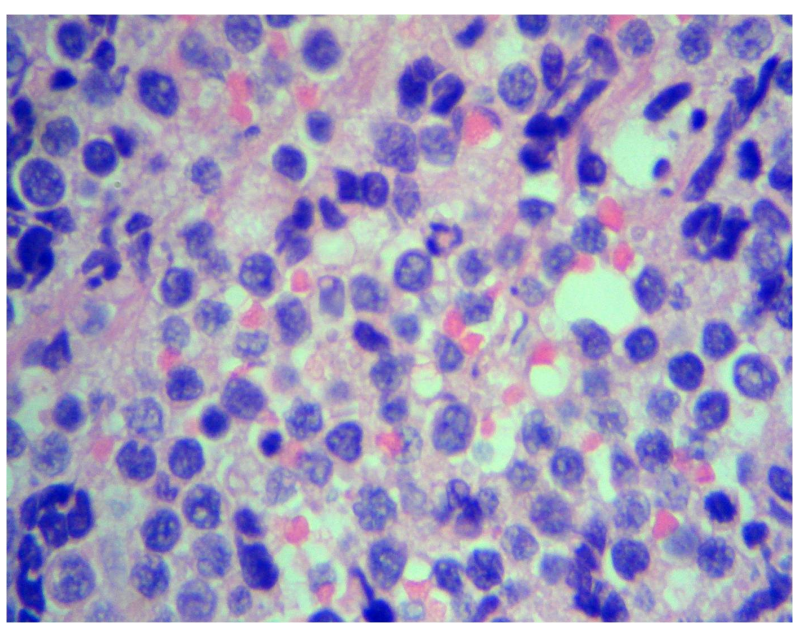

(b)

Figure 1. Diffuse large B-cell lymphoma. H\&E stains show a typical polymorphic centroblastic lymphoma (a) $(40 \times)$ and the centroblastic, monomorphic (b) $(\mathrm{H} \& \mathrm{E}, 40 \times)$. 

with Bone Marrow Infiltration in a Sample Mexican Population

Table 2. Correlation to the immunophenotype and morphological variants to the DLBCL.

\begin{tabular}{cccccc}
\hline \multirow{2}{*}{ Immunophenotype } & \multicolumn{4}{c}{ Morphologic types } & \multirow{2}{*}{ Total } \\
\cline { 2 - 5 } & CB poli & CB mo & IB & Anaplasic & \\
GC & $23(21.2 \%)$ & $5(5.6 \%)$ & $1(0.9 \%)$ & $2(1.8 \%)$ & $31(28.7 \%)$ \\
ABC & $36(33.3 \%)$ & $12(11.1 \%)$ & $8(7.4 \%)$ & $7(6.4 \%)$ & $63(58.3 \%)$ \\
3th Type & $5(4.6 \%)$ & $6(5.5 \%)$ & $1(0.9 \%)$ & $2(1.8 \%)$ & $14(12.9 \%)$ \\
Total & $64(59.2 \%)$ & $23(21.2 \%)$ & $10(9.2 \%)$ & $11(10.1 \%)$ & $108(100 \%)$ \\
\hline
\end{tabular}

$\mathrm{Xi}^{2} 89.18(p=0.178)$.

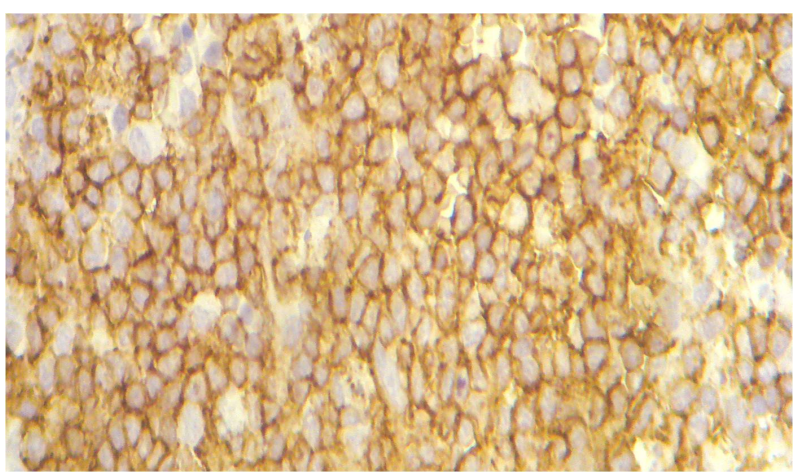

(a)

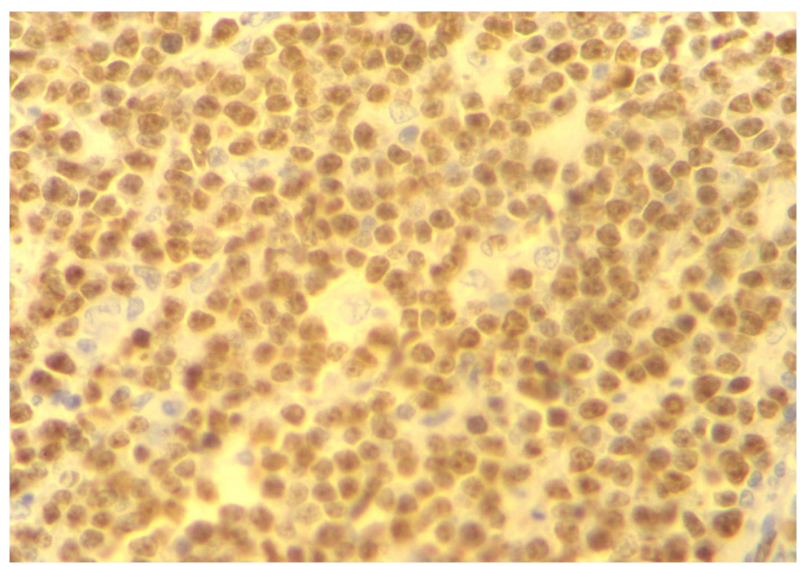

(b)

Figure 2. Immunohistochemical stains for $\mathrm{CD10}+$ (a) expression profiles to the GCB and MUM-1+ (b) protein expression in the DLBCL ABC.

$(9.2 \%)$ germinal center-originating lymphomas infiltrated the BM, whereas 17 of 63 cases deriving from B activated lymphocytes $(15.7 \%)$ infiltrated the BM $(P=0.49)$ (Table 4). Six cases of the total 14 lymphomas expressing only bcl2 showed BM involvement. No statistically significant correlation was found between the expression of CD10, bcl6, bcl2, and MUM-1 markers and the type of infiltration $(P=0.469, P=0.685, P=0.518$, and $P=$ 0.168 , respectively).

Presence of Epstein Barr virus (EBV) was positive in

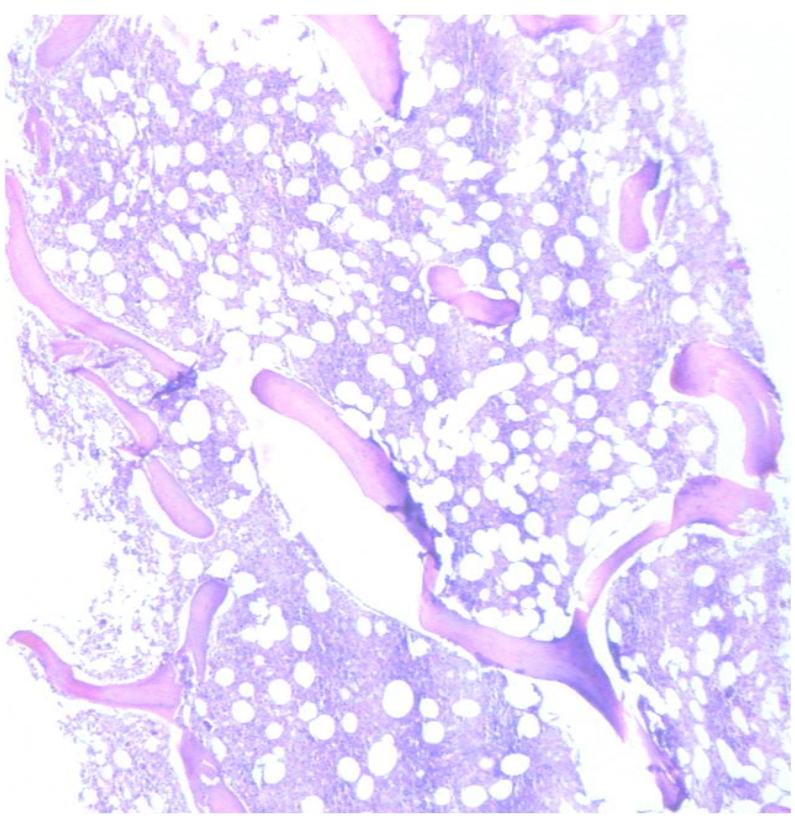

(a)

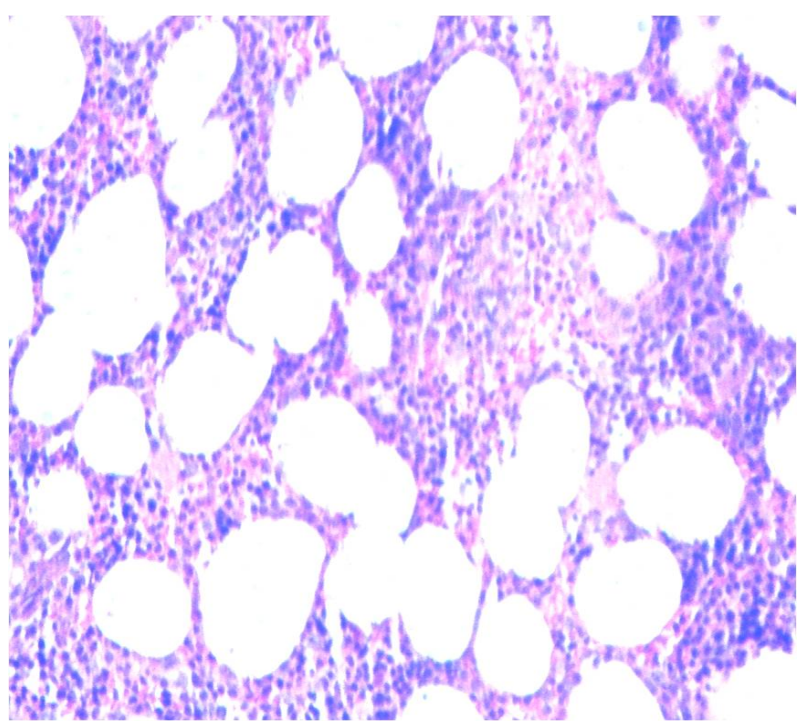

(b)

Figure 3. Discordant infiltration to bone marrow (H\&E) (a) Low power and (b) High power. 


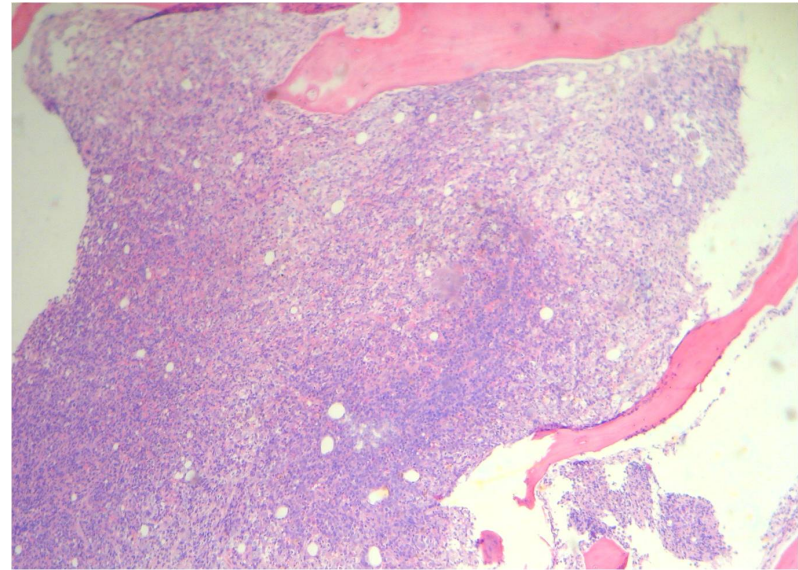

(a)

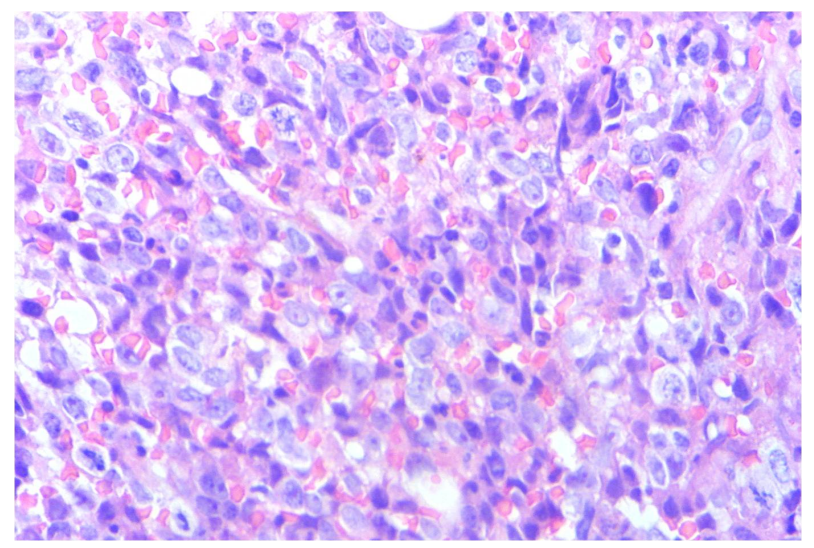

(b)

Figure 4. Concordant infiltration to bone marrow (H\&E) (a) Low power and (b) High power.

Table 3. The morphologic type and bone marrow infiltration of the DLBCL.

\begin{tabular}{cccc}
\hline \multirow{2}{*}{ Morphologic type of D LBCL } & \multicolumn{2}{c}{ Bone marrow infiltration } & \multirow{2}{*}{ N } \\
\cline { 2 - 3 } & Neg & Pos & \\
\hline CB Poli & 48 & 15 & 63 \\
CB mo & 9 & 14 & 23 \\
IB & 7 & 3 & 10 \\
Anaplasic & 10 & 1 & 11 \\
Total & 75 & 33 & 108 \\
$\%$ & 69.2 & 30.6 & 100.0 \\
\hline
\end{tabular}

$\mathrm{Xi}^{2} 13.879(p=0.0003)$.

10 of the 66 patients over 50 years of age (15.1\%) (Figure 5). Morphologically, eight of these cases were classified as CB and two as IB $(P=0.207)$ (Table 5). One case expressed $\mathrm{CD} 10$ and was classified as originating from the GC, whereas seven cases expressed MUM-1 and were considered as derived from $\mathrm{ABC}$. Two cases
Table 4. Type of infiltration to bone marrow and the immunophenotype of the DLBCL.

\begin{tabular}{ccccc}
\hline \multirow{2}{*}{ Infiltration type } & \multicolumn{3}{c}{ Inmunophenotype of DLBCL } & \multirow{2}{*}{ Total } \\
\cline { 2 - 4 } & GC & ABC & Third type & \\
\hline Concordant & 6 & 7 & 2 & 15 \\
Discordant & 4 & 10 & 4 & 18 \\
Non infiltration & 21 & 46 & 8 & 75 \\
Total & 31 & 63 & 14 & 108 \\
\hline
\end{tabular}

$\mathrm{Xi}^{2} 2.930(p=0.570)$

Table 5. Shows the morphologics variants of DLBCL and cases EBER positive in patients older than 50 years old.

\begin{tabular}{cccc}
\hline & & EBER & \\
& Neg & Pos & Total \\
\hline CB pol & 33 & 4 & \\
CB mo & 11 & 4 & \\
IB & 7 & 2 & \\
Anaplasic & 5 & 0 & 66 \\
Total & 56 & 10 & \\
\hline
\end{tabular}

$\mathrm{Xi}^{2} 8.446(p=0.207)$.

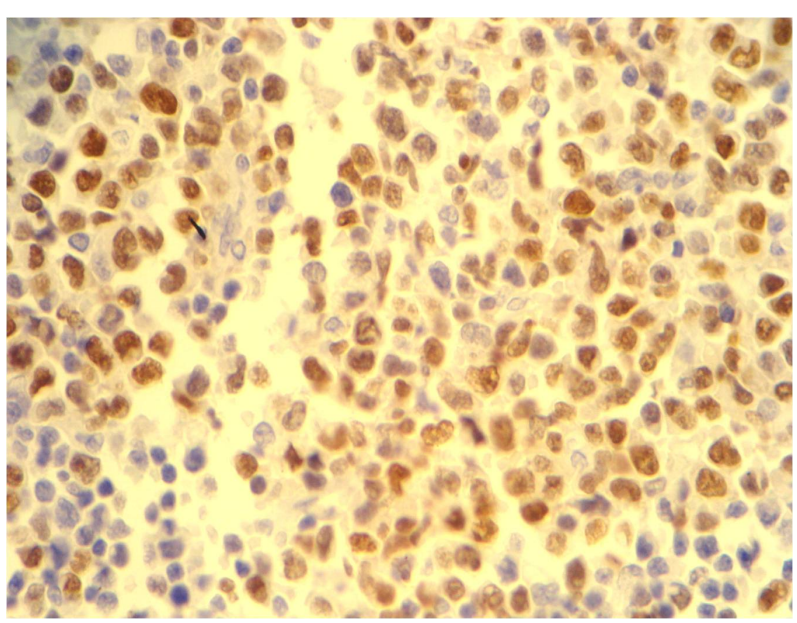

Figure 5. Dako in situ hybridization for Epstein-Barr virus positive case showing brown intranuclear sgnals in DLBCL patients older $\geq \mathbf{5 0}$ years old.

did not express any of the aforementioned markers. Four of these 10 cases showed infiltration to BM, which was of the concordant subtype in one case and discordant in three cases $(P=0.585)$.

\section{Discussion}

The bone marrow involvement by large-B cell lymphoma 
usually occurs in patients with widely disseminated disease. In this study, we associated site (nodal vs. extranodal), morphological variants, and immunohistochemical marker expression with infiltration to BM in patients at the time of diagnosis of the "novo" diffuse large B-cell lymphomas. Our results show that DLBCLs were more frequent in men and mean age at diagnosis was 52 years, which is younger than the age reported for another studies $[1,2,3,15]$. The primary sites most frequently affected were lymph nodes, followed by Waldeyer's ring, which is also in contrast to reports in the article of Höller and cols, where the digestive tube is mentioned as the most frequent extranodal site [15]. The mean age at diagnosis in patients with DLBCL of the digestive tract was 65 years, which proved older than the mean age of 52 years at diagnosis in other primary sites (lymph nodes, Waldeyer's ring, and others). And the mean age at diagnosis of primary DLBCL of the superior aerodigestive tract and others was of 51 and 53 years reported by Wong et al. [16]. BM infiltration was documented in $30.6 \%$ of cases. There are controversial data on the prognostic signifycance of BM involvement in DLBCLs evaluated by conventional histology methods, as it ranges from $11 \%$ to $35 \%[11,12]$. This variability may be related to adequacy of obtained hematopoietic tissue and precision of histopathological reporting [14]. Our results regarding primary site and presence of BM infiltration were not significantly different from findings in other reports. The sites of extranodal lymphomas reported in countries such as Korea, Malaysia, and China are similar to our findings $[17,18]$. Morphologically, the predominant type was the CB variant. Centroblastic morphology was the only morphological variable significantly correlated with $\mathrm{BM}$ infiltration $(P=0.0003)$ and infiltration rates were similar in both $\mathrm{CB}$ subtypes. The second morphological variant was anaplastic lymphoma, which was present in $10 \%$ of cases and showed BM infiltration in one patient. IB subtype was the least frequent morphological variant (9\%) in our study, which is slightly higher than the $4 \%$ frequency reported by a German study group showing poor survival rates in these patients [19]. Plasmacytoid differentiation in immunoblastic lymphomas has been identified as a risk factor [20]. Three of our IB cases showed BM infiltration. Using the antibodies recommended by Hans et al., DLBCLs were classified, on the basis of expression markers, in three immunophenotypes. Germinal center immnunophenotype was found in $29 \%$ of cases, which proved lower than found in other series using the same classification method and reporting 39\% to $49 \%$ cases of $\mathrm{GC}$ phenotype [6,21]. Lymphomas originating from $\mathrm{ABC}$ were the most common (58\%) in our series. Chen et al. found this phenotype in $78.2 \%$ of a 124 patient cohort using two classification algorithms. In this cohort they also found that BCL2 expression was associated with gain of a chromosome region $18 / 18 q$ and $3 / 3 q$ [22].

Some studies $[23,24]$ have shown that the ABC phenotype is more common in DLBCLs of extranodal origin and the presence of this phenotype might account for differences in the development of nodal or extranodal DLBCLs. In our study, as in the study by Chen et al., DLBCLs were more frequently of primary nodal origin. Lymphomas that did not express CD 10, Bcl6, and Mum-1 corresponded to $12.9 \%$ of cases.

Correlation of immunophenotype and BM infiltration showed that the $\mathrm{ABC}$ phenotype was most frequently associated with BM infiltration (15.7\%), followed by GC phenotype $(9.2 \%)$, and the third type (5.5\%). Infiltration patterns in bone marrow range from focal infiltrates to complete substitution of hematopoietic elements. Discordant involvement with presence of large cells in the primary tissue and small cells in bone marrow infiltrates has been recognized in DLBCL, and is encountered in 50 to $70 \%$ of cases in different series $[12,21,25]$. Routine stains identified the lymphoid infiltrate, although eight cases required immunohistochemical technique with the follow antibodies: CD 20, CD2 and CD5. The impact of bone marrow involvement varies and has prognostic value in cases of DLBCLs; it has been suggested that bone marrow involvement affects the international prognostic index (IPI) as it places the disease in clinical stage IV [25]. Immunohistochemistry and flow cytometry results from bone marrow aspirates have documented the presence of up to $11 \%$ of lymphoid neoplastic cells of unclear morphology [26,27]. The prognostic differences of the GC and ABC phenotypes must be reevaluated, since they were assed in the era before rituximab [28]. In the near future, it will be important to study correlations between immunohistological markers, bone marrow involvement at the time of diagnosis, and response to clinical treatment. Molecular and genetic alterations encountered in these types of lymphomas include chromosomic translocations that frequently involve the immunoglobulin locus, resulting in dysregulation of proto-ocogenes (c-MYC, BCL2, BCL6 and others) and gene mutations that involve key functions of normal B-cells. These mutations resist a characteristic pattern of somatic hypermutations, a process involving Ig genes in the differenttiation of B cells. These alterations are observed at the origin of the errors occurring during physiological events involved in the diversification repertoire of the germinal center, during class switch recombination (CSR) or somatic hypermutation (SHM) [28,29]. Experimental studies on animal models have confirmed the critical roll played by the induced activation of the cytidine deaminase enzyme in the physiology of CSR and SHM in the development of lymphoid tumors [30,31]. 
Epstein-Barr virus-positive DLBCL of the elderly has been separated from DLBCL, not otherwise specified, in the current 2008 WHO classification [1], and occurs in patients with no known history of immunodeficiency or other lymphoproliferative process. An $8 \%$ to $10 \%$ frequency has been reported in Asian series [32] but there are few data in westerns countries. In this study, in-situ hybridization studies were performed in 66 patients older than 50 years and presence of nuclear Epstein Barr Virus was detected in 10 patients (15.1\%). These results are similar to those found in Asian literature and in a recent study by Quintanilla et al., who reported a 7\% prevalence in Mexican patients [33]. The proportion of Epstein Barr positive cases increases with age; in a recent study in a Latin American country the mean onset age was 75 years and cases were classified as DLBCL of germinal center phenotype [34]. It is suggested that this increased incidence may be related to immunological damage or senescence as part of the aging process. Seventy percent of patients with EBV associated DLBCLs have extranodal disease (skin, lung, tonsils, and stomach) and 30\% have primarily nodal disease. In this study, 9 patients presented lymph nodes as the primary site, whereas in one patient the primary site was the digestive tract. Regarding morphology, Epstein Barr-positive DLBCL cases were of the polymorphic centroblastic subtype. There was BM infiltration in four cases, three of them of the discordant type and one case had concordant involvement. It has been observed that the presence of EBV in DLCBLs is related to poor clinical outcome [35]. In this study the presence of EBV was related to DLBCLs of poor prognosis. In an another recent paper of Peru the authors reports 7 patients with de novo DLBCL and infection with HTLV-1 carriers and EBV infection, is it interesant by the rare association [36].

In conclusion, there is scarce information in Latin America countries on the morphology and immunophenotypes of DLBCLs. Furthermore, there are few reports on the incidence and type of bone marrow involvement, and our study could have an impact on the initial diagnosis as well as for the clinical stratification of patients, since BM infiltration may have a negative impact on survival rate in patients with this type of lymphomas and recent data support the concept that molecular subtyping of diffuse large B-cell lymphoma is clinically relevant.

\section{Acknowledgements}

This study was supported by the Research Department of the General Hospital of Mexico (Dic/09/310/03/114).

\section{REFERENCES}

[1] E. Campo, S. H. Swerdlow, N. L. Harris, S. Pileri, H.
Stein and E. S. Jaffe, "The 2008 WHO Classification of Lymphoid Neoplasms and Beyond: Evolving Concepts and Practical Applications," Blood, Vol. 117, No. 19, 2011, pp. 5019-5032. doi:10.1182/blood-2011-01-293050

[2] E. Zucca, E. Roggero, F. Bertoni, et al., "Primary Extranodal Non-Hodgkin's Lymphomas. Part I: Gastrointestinal, Cutaneous and Genitourinary Lymphomas," Annals of Oncology, Vol. 8, No. 8, 1997, pp. 727-737. doi:10.1023/A:1008282818705

[3] M. B. Romero-Guadarrama, M. M. Hernández-González, M. A. Durán-Padilla, et al., "Linfoma B Difuso de Células Grandes. Características Patológicas y de Inmunofenotipo en 148 Pacientes Estudiados en el Hospital General de México," Revisa Medica Hospital General de México, SS, Vol. 69, No. 4, 2006, pp. 192-198.

[4] A. C. Feller and J. Diebold, "Histopathology of Nodal and Extranodal Non-Hodkgin's Lymphomas: Based on the WHO Classification," 3rd Edition, Springer-Verlag, Berlin-Heidelberg, 2004, pp. 75-99.

[5] K. Offit, F. Lococo, D. C. Lovie, N. Z. Parsa, D. Leung, et al., "Rearrangement of the bcl-6 Gene as a Prognostic Marker in Diffuse Large-Cell Lymphoma," The New England Journal of Medicine, Vol. 331, 1994, pp. 74-80. doi:10.1056/NEJM199407143310202

[6] M. G. Tibiletti, V. Martin, B. Bermasconi, B. Del Curto, L. Pecciarin, et al., "BCL2, BCL6, MYC, MALT 1 and BCL10 Rearrangements in Nodal Diffuse Large B-Cell Lymphomas: A Multicenter Evaluation of a New Set of Fluorescent in Situ Hybridization Probes and Correlation with Clinical Outcome," Human Pathology, Vol. 40, No. 5, 2009, pp. 645-652. doi:10.1016/j.humpath.2008.06.032

[7] C. P. Hans, D. D. Weissenburger, T. C. Greiner, et al., "Confirmation of the Molecular Classification of Diffuse Large B-Cell Lymphoma by Immunohistochemistry Using a Tissue Microarray," Blood, Vol. 103, No. 1, 2003, pp. 275-282. doi:10.1182/blood-2003-05-1545

[8] D. Talaulikar, J. E. Dahlstrom, B. Shadbolt, M. McNiven, A. Broomfeld, et al., "Occult Bone Marrow Involvement in Patients with Diffuse Large B-Cell Lymphoma Results of a Pilot Study," Pathology, Vol. 39, No. 6, 2007, pp. 580-585. doi:10.1080/00313020701684417

[9] M. G. Conlan, M. Bast, J. O. Armitage and D. D. Weisenburger, "Bone Marrow Involvement by Non-Hodgkin's Lymphoma: The Clinical Significance of Morphologic Discordance between the Lymph Node and Bone Marrow. Nebraska Lymphoma Study Group," Journal of Clinical Oncology, Vol. 8, No. 7, 1990, pp. 1163-1172.

[10] J. Campbell, J. F. Seymour, J. Matheews, M. Wolf, J. Stone and S. Juneja, "The Prognostic Impact of Bone Marrow Involvement in Patients with Diffuse Large Cell Lymphoma Varies According to the Degree of Infiltration and Presence of Discordant Marrow Involvement," European Journal of Haematology, Vol. 76, No. 6, 2006, pp. 473-480. doi:10.1111/j.1600-0609.2006.00644.x

[11] D. A. Arber and T. I. George, "Bone Marrow Biopsy Involvement by Non-Hodgkin's Lymphoma: Frequency of Lymphoma Types, Patterns, Blood Involvement, and Discordance with Other Sites in 450 Specimens," The 
American Journal of Surgical Pathology, Vol. 29, No. 12, 2005, pp. 1549-1557. doi:10.1097/01.pas.0000182405.65041.8b

[12] R. Chung, R. Lai, P. Wei, et al., "Concordant but Not Discordant Bone Marrow Involvement in Diffuse Large B-Cell Lymphoma Predicts a Poor Clinical Outcome Independent of the International Prognostic Index," Blood, Vol. 110, No. 4, 2007, pp. 1278-1282. doi:10.1182/blood-2007-01-070300

[13] C. Palacio, G. Acevedo, M. Navarrete, et al., "Flow Cytometry in the Bone Marrow Evaluation of Follicular and Diffuse Large B-Cell Lymphomas," Haematologica, Vol. 86, No. 9, 2001, pp. 934-940.

[14] T. Dipti and J. E. Dahlstrom, "Staging Bone Marrow in Diffuse Large B-Cell Lymphoma: The Role of Ancillary Investigations," Pathology, Vol. 41, No. 3, 2009, pp. 214222. doi:10.1080/00313020902756295

[15] S. Höller, H. Horn, A. Lohr, U. Mäder, T. Katzenberger, et al., "A Cytomorphological and Immunohistochemical Profile of Aggressive B-Cell Lymphoma: High Clinical Impact of a Cumulative Immunohistochemical Outcome Predictor Score," Journal of Hematopathology, Vol. 2, No. 4, 2009, pp. 187-194. doi:10.1007/s12308-009-0044-x

[16] K. K. Wong, N. Prepageran and S. C. Peh, "Prognostic Subgroup Distribution in Diffuse Large B-Cell Lymphoma of the Upper Aerodigestive Tract," Pathology, Vol. 41, No. 2, 2009, pp. 133-139. doi: $10.1080 / 00313020802436790$

[17] J. E. Kim, J. A. Kim, Y. K. Jeon, S. S. Park, D. S. Heo and C.W. Kim, "Comparative Analysis or NK/T Cell Lymphoma and Peripheral T-Cell Lymphoma in Korea: Clinicopathological Correlations and Analysis of EBV Strain Type and 30-bp Deletion Variant LMO1," Pathology International, Vol. 53, 2003, pp. 735-743.

[18] S.-C. Peh, G.-G. Gan, L.-K. Lee and G.-I. Eow, "Clinical Relevance of CD 10, BCL6 and Multiple Myeloma-1 Expression in Diffuse Large B-Cell Lymphomas in Malaysia," Pathology International, Vol. 58, No. 9, 2008, pp. 572-579. doi:10.1111/j.1440-1827.2008.02273.x

[19] M. Engelhard, G. Brittinger, D. Huhn, et al., "Subclassification of Diffuse Large B-Cell Lymphomas According to the Kiel Classification: Distinction of Centroblastic and Immunoblastic Lymphomas Is a Significant Prognostic Risk Factor," Blood, Vol. 89, No. 7, 1997, pp. 2291-2297.

[20] J. Diebold, J. R. Anderson, J. O. Armitage, J. M. Connors, K. A. MacLennan, et al., "Diffuse Large B-Cell Lymphoma: A Clinicopathologic Analysis of 444 Cases Classified According to the Updated Kiel Classification," Leukemia and Lymphoma, Vol. 43, No. 1, 2002, pp. 97-104. doi:10.1080/10428190210173

[21] J. W. Sweetenham, "Molecular Signatures in the Diagnsis and Management of Diffuse Large B-Cell Lymphoma," Current Opinion in Hematology, Vol. 18, No. 4, 2011, pp. 288-292. doi:10.1097/MOH.0b013e32834706ee

[22] Y. Chen, T. Han, J. Iqbal, R. Irons, C. C Wing, et al., "Diffuse Large B-Cell Lymphoma in Chinese Patients. Immunophenotypic and Cytogenetic Analyses of 124
Cases," American Journal of Clinical Pathology, Vol. 133, No. 2, 2010, pp. 305-313. doi:10.1309/AJCP4H6ADGYDZMOA

[23] S. Camilleri-Broet, E. Criniere, P. Broet, et al., "A Uniform Activated B-Cell-Like Immunophenotype Might Explain the Poor Prognosis of Primary Central Nervous System Lymphomas: Analysis of 83 Cases," Blood, Vol. 107, No. 1, 2006, pp. 190-196. doi:10.1182/blood-2005-03-1024

[24] M. A. Al-Abbadi, E. M. Hattab, M. S. Tarrawneh, et al., "Primary Testicular Diffuse Large B-Cell Lymphoma Shows a Non-Germinal Center B-Cell-Like Subgroup: A Study of 18 Cases," Modern Pathology, Vol. 19, No. 12, 2006, pp. 1521-1527. doi:10.1038/modpathol.3800691

[25] G. Paone, E. Itti, C. Haioun, P. Gaulard, J. Dupuis, et al., "Bone Marrow Involvement in Diffuse Large B-Cell Lymphoma: Correlation between FDG-PET Uptake and Type of Cellular Infiltrate," European Journal of Nuclear Medicine and Molecular Imaging, Vol. 36, No. 5, 2009, pp. 745-750. doi:10.1007/s00259-008-1021-9

[26] Y. Yan, W. C. Chan, D. D. Weisenburger, J. R. Anderson, M. A. Bast, et al., "Clinical and Prognostic Significance of Bone Marrow Involvement in Patients with Diffuse Aggressive B-Cell Lymphoma," Journal of Clinical Oncology, Vol. 13, No. 6, 1995, pp. 1336-1342.

[27] D. Talaulikar, J. E. Dahistrom, B. Shadholt, A. Broomfield and A. Mc Donald, "Role of Immunohistochemistry in Staging Diffuse Large B-Cell Lymphoma," Journal of Histochemistry and Cytochemistry, Vol. 56, No. 10, 2008, pp. 893-900. doi:10.1369/jhc.2008.951087

[28] A. Hagenbeek, R. D. Gascoyne, M. Dreyling, P. Kluin, A. Engert and G. Salles, "Biomarkers and Prognosis in Malignant Lymphomas," Clinical Lymphoma Myeloma and Leukemia, Vol. 9, No. 2, 2009, pp. 160-166.

[29] A. Nussenzweig and M. C. Nussenzweig, "Origin of Chromosomal Translocations in Lymphoid Cancer," Cell, Vol. 141, No. 1, 2010, pp. 27-38. doi:10.1016/j.cell.2010.03.016

[30] L. Pasqualucci, G. Bhagat, M. Jankovic, et al., "AID Is Required for Germinal Center-Derived Lymphomagenesis," Nature Genetics, Vol. 40, No. 1, 2008, pp. 108-112. doi:10.1038/ng.2007.35

[31] O. A. O'Connor, L. E. Toner, R. Vrhovac, T. BudakAlpdogan, E. A. Smith and P. Bergman, "Comparative Animal Models for the Study of Lymphohematopoietic Tumors: Strengths and Limitations of Present Approaches," Leukemia and Lymphoma, Vol. 46, No. 7, 2005, pp. 973992. doi:10.1080/10428190500083193

[32] T. Oyama, K. Ichimura, R. Suzuki, J. Suzumiya, K. Ohshima, et al., "Age-Related EBV-Associated B-Cell Lymphoproliferative Disorders Constitute a Distinct Clinicopathologic Group: A study of 96 Patients," Clinical Cancer Research, Vol. 13, No. 17, 2007, pp. 5124-5132. doi:10.1158/1078-0432.CCR-06-2823

[33] A. Hofscheier, A. Ponciano, I. Bonzheim, P. Adam, C. Lome-Maldonado, et al., "Geographic Variation in the Prevalence of Epstein-Barr Virus-Positive Diffuse Large B-Cell Lymphoma of the Elderly: A Comparative Analy- 

with Bone Marrow Infiltration in a Sample Mexican Population

sis of A Mexican and German Population," Modern Pathology, Vol. 24, No. 8, 2011, pp. 1046-1054. doi:10.1038/modpathol.663-667.62

[34] B. E. Beltran, J. J. Castillo, D. Morales., F. H. De Mendoza, P. Quiñones, et al., "EBV-Positive Diffuse Large B-Cell Lymphoma of the Elderly: A Case Series from Peru," American Journal of Hematology, Vol. 86, No. 8, 2011, pp. 663-667. doi:10.1002/ajh.22078

[35] S. Park, J. Lee, Y. H. Ko, et al., "The Impact of Ep-
stein-Barr Virus Status on Clinical outcome in Diffuse Large B-Cell Lymphoma," Blood, Vol. 110, No. 3, 2007, pp. 972-978. doi:10.1182/blood-2007-01-067769

[36] B. E. Beltran, P. Quiñones, D. Morales, J. C. Revilla, et al., "Diffuse Large B-Cell Lymphoma in Human T-Lymphotropic Virus Type 1 Carriers," Leukemia Research and Treatment, Vol. 2012, 2012, 4 pages. doi: $10.1155 / 2012 / 262363$

$\begin{array}{llll}\text { Abbreviations, Nomenclature, and Symbols } & \text { IB } & \text { Immunoblastic } \\ \text { DLBCL } & \text { Diffuse large B cell lymphoma } & \text { GC } & \text { Germinal center } \\ \text { EBER } & \text { In situ hibridization techique to detect Epstein- } & \text { ABC } & \text { Activated B cells } \\ & \text { Barr virus } & \text { CB pol } & \text { polymorphic centroblastic } \\ \text { PCR } & \text { Polymerase chain reaction } & \text { CB mo } & \text { monomorphic centroblastic } \\ \text { BM } & \text { Bone marrow } & \text { Neg } & \text { negative } \\ \text { CB } & \text { Centroblastic } & \text { Pos } & \text { positive }\end{array}$

